Check for updates

Cite this: RSC Adv., 2018, 8, 23339

\title{
A multiscale hydrothermal carbon layer modified carbon fiber for composite fabrication $\uparrow$
}

\author{
Xianfeng Xi, (D) ab Yousi Chen, ${ }^{a}$ Jie Wang, ${ }^{\text {ab }}$ Yaoyao Li, ${ }^{\text {ab }}$ Xiangdong Shao, ${ }^{c} L_{i u ~ H e}$, ${ }^{\text {a }}$ \\ Qing Huang (D)*a and Xueliang Pei ${ }^{\star a}$
}

A novel multiscale hydrothermal carbon layer (MHTCL) for carbon fiber (CF) surface modification was developed. The MHTCL is a multiscale high-disorder amorphous carbon coating with a colored appearance, abundant functional groups, multiscale roughness, a large specific surface area, a high surface energy, and good wetting ability. The O/C atom ratios of the MHTCL-modified CF were in the range of $0.17-0.23$, and the functional groups were mainly $\mathrm{C}-\mathrm{O}$ and $\mathrm{C}=\mathrm{O}$ groups. During the lowconcentration glucose hydrothermal treatment with the carbon fibers (CFs), the glucose generates furan derivative intermediates, which adsorb on the surface of the CFs and carbonize continuously, finally forming the MHTCL on the CFs. The fracture and rupture of the MHTCL during the forming process produce new nucleation centers on the CF surface, which result in abundant multiscale irregular particles. The MHTCL is a facile method for the modification of CFs. The fabrication of the CF composites demonstrated that the MHTCL obviously increases the interlaminar shear strength of the CF/ polyimide composite and the interfacial interaction of the CF and polyetheretherketone.

Received 13th May 2018

Accepted 20th June 2018

DOI: $10.1039 / \mathrm{c} 8 \mathrm{ra0} 4064 \mathrm{~h}$

rsc.li/rsc-advances
$\mathrm{CF} /$ epoxy, ${ }^{\mathbf{1 0}}$ polyetherimide (PEI) for CF/polyetheretherketone, ${ }^{\mathbf{1 1}}$ polypropylene-g-maleic anhydride for $\mathrm{CF} /$ polypropylene, ${ }^{\mathbf{1 2}}$ polyethylene- $g$-maleic anhydride for $\mathrm{CF} /$ polyethylene, and polyether sulfone for $\mathrm{CF} /$ polyether sulfone..$^{\mathbf{1 3}, \mathbf{1 4}}$ However, commercial polymer sizings have been shown to decrease the surface tension and quantity of functional groups of the CFs, which may lead to weak CF wettability and poor composite interfacial shear strength. ${ }^{15,16}$ Our recent research on PEI sizing indicated that dewetting of the PEI particles on the CF substrate occurred at the melting point of the polymer (Fig. S6, ESI $\dagger$ ); similar phenomena have been researched for many years in the physics field. ${ }^{17}$ The dewetting of the polymer on the surface of CFs means poor interfacial adhesion. ${ }^{18}$ Surface chemical modification of CF is also a typical approach used in this field, such as surface oxidation, ${ }^{19}$ electrochemical treatment, ${ }^{20}$ plasma etching, ${ }^{21,22}$ or high-energy irradiation chemical grafting. ${ }^{23,24}$ The surface chemical modification increases the number of functional groups on the CF surface but decreases the single fiber tensile strength. Carbon layers on CFs have also been frequently reported for $\mathrm{CF}$ composite fabrication. Graphene (GE) coating, ${ }^{25}$ carbon nanotube (CNT) coating, and situ chemical vapor deposition (CVD) CNT coating have been reported to improve the composite performance ${ }^{26-28}$ by increasing the surface area and roughness of the CFs. However, these approaches are not efficient for large-scale fabrication.

Hydrothermal carbon (HTC) materials have plentiful surface functional groups and reproducible resources ${ }^{29}$ and have attracted considerable interest from researchers studying heavy metal absorption, ${ }^{30}$ catalyst supports, ${ }^{31-33}$ battery anodes, ${ }^{34-36}$ 
Table 1 Summary of hydrothermal treatment samples

\begin{tabular}{|c|c|c|c|c|}
\hline Samples & $\begin{array}{l}\text { Glucose solution } \\
\text { concentration } \mathrm{g} \mathrm{L}^{-1}\end{array}$ & $\begin{array}{l}\text { Hot treatment } \\
\text { at } 673 \mathrm{~K}\end{array}$ & Color of the CFs ${ }^{b}$ & $\begin{array}{l}\text { Residues in } \\
\text { the tubes }\end{array}$ \\
\hline CF1 & Untreated & No & Black & - \\
\hline $\mathrm{CFH} 2^{a}$ & 2 & Yes & Black & - \\
\hline CF3 & 5 & No & Colored & Dispersion \\
\hline $\mathrm{CFH}^{a}{ }^{a}$ & 5 & Yes & Black & - \\
\hline CF5 & 15 & No & Colored & Sediment \\
\hline CF6 & 20 & No & Colored & Sediment \\
\hline CF7 & 30 & No & Colored & Sediment \\
\hline CF8 & 40 & No & Colored & Sediment \\
\hline $\mathrm{NCF}^{c}$ & 2 & - & None CFs & Clarified \\
\hline NCF10 ${ }^{c}$ & 5 & - & None CFs & Clarified \\
\hline
\end{tabular}

${ }^{a}$ The code $\mathrm{CFH}$ means that the CF sample was treated at $673 \mathrm{~K}$ for $4 \mathrm{~h}$ in a nitrogen-based atmosphere. ${ }^{b}$ The CFs were colorized after hydrothermal treatment but turned black after hot treatment in nitrogen. ${ }^{c}$ NCF9, NCF10, and NCF11 were the glucose solutions, which were treated using the same method without CFs.

sensing, semiconductors, and drug delivery. ${ }^{37}$ However, very few papers on materials modified by HTC have been published.

In this study, a multiscale hydrothermal carbon layer (MHTCL) on CFs was fabricated for the first time via simple hydrothermal treatment of unsized CFs in glucose solution. The MHTCL was verified to be a high-disorder amorphous carbon layer with abundant polar organic groups and multiscale roughness. The forming mechanism of the MHTCL is also discussed. The fabrication of the CF composites indicates that coating with MHTCL can be used as an effective modification method for CFs.

\section{Experiments}

\subsection{Pretreatment of CFs}

The received T700 CF tows (ZhongFu ShenYing Co., China) were extracted with acetone (Sigma-Aldrich) in a Soxhlet extraction equipment at $358 \mathrm{~K}$ for $24 \mathrm{~h}$. After washing with deionized water $(\rho \geq 10 \mathrm{M} \Omega \mathrm{cm})$, the $\mathrm{CF}$ tows were dried in a vacuum oven at 323 $\mathrm{K}$ for $12 \mathrm{~h}$. The unsized CF tows were stored in a glass desiccator with silica-gel desiccant.

\subsection{Hydrothermal treatment of unsized CFs}

Glucose (Sigma-Aldrich) was used as the precursor for the MHTCL. The glucose was dissolved in deionized water with a concentration of $2-40 \mathrm{gL}^{-1}$. The unsized $\mathrm{CF}$ tows were placed into glucose solutions in clean glass test tubes and sealed with silicone rubber plugs and then sealed in a $2000 \mathrm{ml}$ stainless steel (AISI 316L) autoclave half-filled with $1000 \mathrm{ml}$ of deionized water. The autoclave was placed into a pre-heated oil bath and heated at $473 \mathrm{~K}$ for $4 \mathrm{~h}$. The equipment is shown in Fig. S1. $\dagger$

After the hydrothermal carbonization, the MHTCLmodified CFs were clipped out of the tubes with tweezers and washed five times in abundant ethyl alcohol (SigmaAldrich) and deionized water, sequentially, and then dried at $323 \mathrm{~K}$ for $12 \mathrm{~h}$. Some of the MHTCL-modified CFs and sediment samples were heat-treated at $673 \mathrm{~K}$ for $4 \mathrm{~h}$ in a nitrogen atmosphere tube furnace to decompose the organic groups. The sample codes and concentrations of the glucose solutions used in the experiment are listed in Table 1.

\subsection{Fabrication of CF-reinforced polyimide composites}

First, $20 \mathrm{~g}$ polyimide (PI) powder (Changchun Institute of Applied Chemistry, CAS) was dissolved in $200 \mathrm{~g}$ of 1-methyl-2pyrrolidinone (Sigma-Aldrich) at $353 \mathrm{~K}$. The CF tow fragments (approximately 300000 fibers per sample) were placed into a Teflon mold, and the hot 1-methyl-2-pyrrolidinone/PI solution was then poured into the mold. The product was then dried at $353 \mathrm{~K}$ for $24 \mathrm{~h}$ and then at $373 \mathrm{~K}$ for $24 \mathrm{~h}$. After removal from the mold, the samples were dipped in the hot PI solution in a vacuum oven for $1 \mathrm{~h}$ and in air for $1 \mathrm{~h}$. Then, the samples were dried at $353 \mathrm{~K}$ for $24 \mathrm{~h}$, at $373 \mathrm{~K}$ for $24 \mathrm{~h}$, at $423 \mathrm{~K}$ for $24 \mathrm{~h}$, and then at $473 \mathrm{~K}$ for 1 week in drying oven. The composites contained approximately $60 \mathrm{wt} \% \mathrm{CFs}$.

\subsection{Fabrication of CF-reinforced polyetheretherketone composites}

Composite samples were prepared by hot press molding, ${ }^{25}$ the strands of unsized CFs and excess polyetheretherketone (PEEK) powder (P450, Victrex Co.) were placed into a stainless mold previously coated with the remolding agent, and then, the mold was placed between two plates of an automatic press vulcanizer that was previously heated to $673 \mathrm{~K}$. The two plates were kept in contact with the mold for $15 \mathrm{~min}$ to allow the PEEK to melt uniformly. Then, $6 \mathrm{MPa}$ of pressure was applied for $30 \mathrm{~s}$ to allow the PEEK to impregnate the CFs. The samples were air cooled at room temperature.

\subsection{Scanning electron microscopy analysis}

The samples were examined using scanning electron microscopy (SEM; Hitachi 4800, Japan) at an accelerating voltage of 5-8 $\mathrm{kV}$. To reduce charging during SEM imaging, the samples were 
pasted onto aluminum stubs using conductive adhesive tape and sputtered with platinum.

The SEM images of CFs in Fig. 1(c and d) and S3† were obtained using another scanning electron microscope (TM1000, Japan) using an accelerating voltage of $15 \mathrm{kV}$.

\subsection{Raman spectroscopy analysis}

Raman spectroscopy measurements were performed using a Renishaw inVia Reflex confocal Raman microscope working at an excitation wavelength of $542 \mathrm{~nm}$. Deconvolution of the spectra was performed by assuming mixed Gaussian/Lorentzian peaks to describe both the main $\mathrm{D}$ and $\mathrm{G}$ bands. The data treatment was performed using Origin Pro 2015 software.

\subsection{X-ray photoelectron spectroscopy analysis}

The X-ray photoelectron spectroscopy (XPS) measurements were recorded on a AXIS ULTRA X-ray photoelectron spectrometer using a $\mathrm{Mg} \mathrm{K} \alpha$ X-ray source $(1253.6 \mathrm{eV}$ ) operated at $14 \mathrm{kV}$ and
$300 \mathrm{~W}$ with an emission current of $25 \mathrm{~mA}$. Survey scans were collected from 0 to $1100 \mathrm{eV}$. Casa XPS instrument software was used for the deconvolution of XPS spectra. For calibration purposes, the $\mathrm{C}$ 1s electron binding energy from adsorbed ubiquitous organic material was referenced at $284.6 \mathrm{eV}$. Different functional groups were assigned using reported C 1s chemical shifts for various organic compounds. The relative amounts of these groups were estimated from respective areas of the assumed Gaussian/Lorentzian curves. The C 1s XPS spectra in Fig. S5† were not calibrated.

\subsection{Surface energy analysis}

The dispersive component, polar component, and total surface energy of the MHTCL-modified CFs was determined using dynamic contact Angle analysis (DCAA) of the MHTCL-modified CFs in the pure liquids using a DCAT21 dynamics contact angle analyzer, Data Physics Co. Six fibers with lengths of approximately $5 \mathrm{~mm}$ were first bonded to double-sided tape with

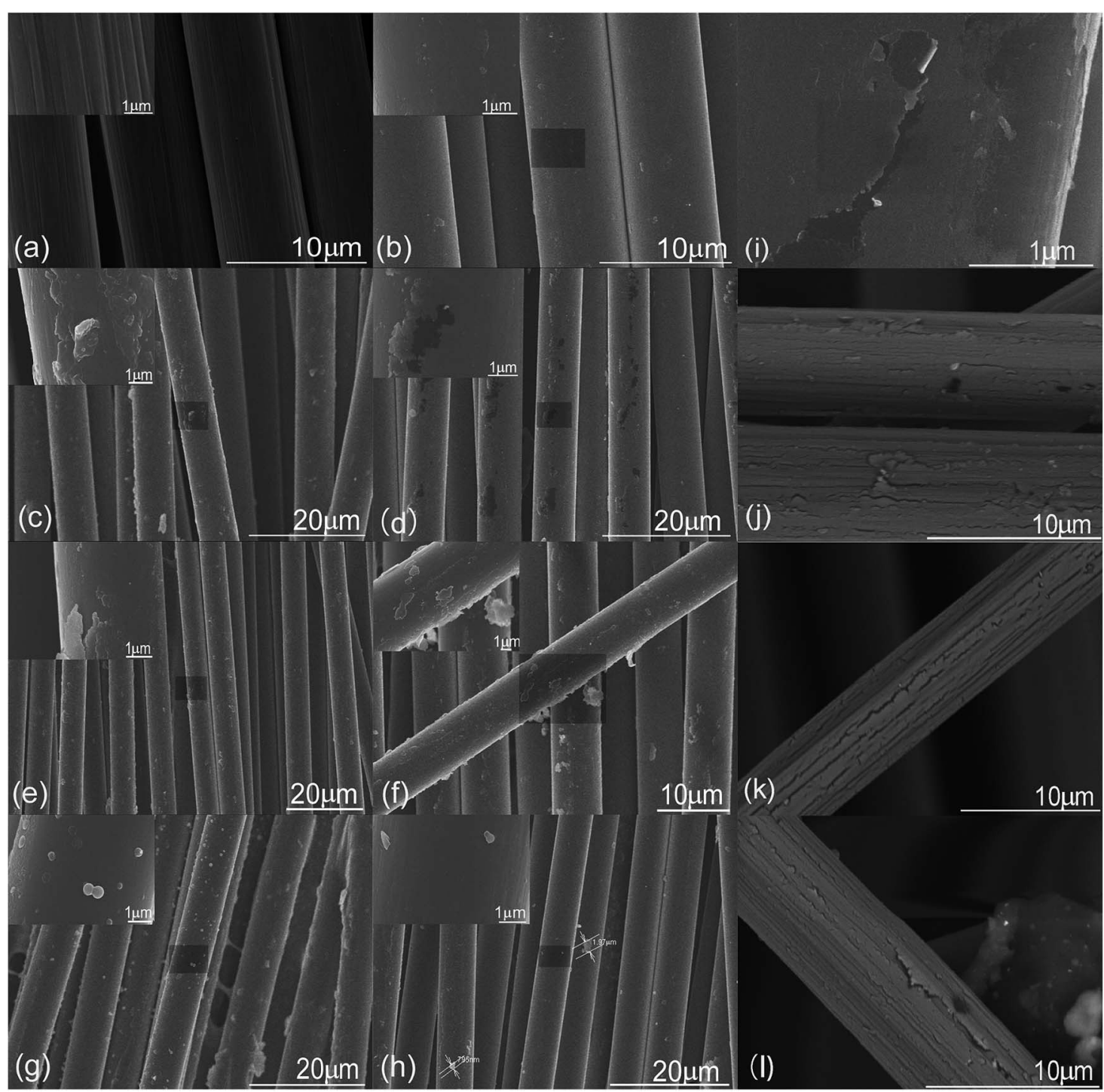

Fig. 1 SEM images of samples (a) CF1, (b) CF2, (c) CF3, (d) CF4, (e) CF5, (f) CF6, (g) CF7 and (h) CF8. Images (i-l) were selected from sample CF4 to highlight the fractures of the MHTCL. 
proportional spacing and trimmed on one side of the fibers. Then, the assembly was hung on the arm of the electronic balance. The DCAA experiments were performed using a motor speed of $0.1 \mathrm{~mm} \mathrm{~s}^{-1}$ and fiber immersion depth of $4 \mathrm{~mm}$ with deionized water and diiodomethane (Sigma-Aldrich) as the wetting medium. The five separate results for the tested fiber samples were averaged to obtain one representative value. The advancing contact angle was used to calculate the fiber surface energy using the OWRK equation in the SCAT software package supplied by Data Physics.

\subsection{Specific surface area analysis}

The specific surface areas of the samples were determined by physical adsorption $\left(\mathrm{N}_{2}\right.$ at $\left.-77.7 \mathrm{~K}\right)$ using a Micrometrics ASAP 2020 HD88 physisorption analyzer, after outgassing the samples at $353 \mathrm{~K}$ under vacuum for $5 \mathrm{~h}$.

\subsection{Short beam shear test}

Three-point short beam shear tests were performed on an Instron mechanical test machine (Instron 5985). The composite laminate samples were incised and polished to the standard size in accordance with ASTM D2344. The sample dimensions were $3 \mathrm{~mm} \times 6 \mathrm{~mm} \times 15 \mathrm{~mm}$.

\section{Results and discussion}

The MHTCL formed on the CF surface in a very low concentration solution of the glucose at $473 \mathrm{~K}$, as indicated in Table 1. The CF samples hydrothermally treated by the glucose solution were colored (Fig. S2, ESI $\dagger$ ), because of the organic functional groups located on the mini-sized carbon structure of the MHTCL.

After the hot treatment in nitrogen gas at $673 \mathrm{~K}$, the organic groups decomposed, and the colored characteristic disappeared and the CFs finally turned black. After standing for $24 \mathrm{~h}$, the residual solutions of the hydrothermal treatment were examined, and the observations are described in Table 1. The residual hydrothermal solutions were still cloudy dispersions if the concentrations of the glucose solutions were below $10 \mathrm{~g} \mathrm{~L}^{-1}$; however, the residual solutions were clarified with sediments at the bottom of the tubes if the concentrations were above $15 \mathrm{~g}$ $\mathrm{L}^{-1}$ (Fig. S1, ESI $\dagger$ ). The sediments were confirmed to be an accumulation of hydrothermal carbon spheres by Raman spectroscopy and SEM (Fig. S3, ESI $\dagger$ ). However, the residue solutions were clarified without sediment if the CFs were absent during the hydrothermal treatment, which indicates that the hydrothermal spheres had not formed.

\subsection{SEM analysis of MHTCL-modified CFS}

The SEM images in Fig. 1 show the topographies of the unsized CFs and MHTCL-modified CFs. The unsized T700 CFs in this study had vast shallow grooves. The grooves disappeared and HTC covered the surface of the CFs after hydrothermal treatment in the $2 \mathrm{~g} \mathrm{~L}^{-1}$ glucose solution, as observed in Fig. 1(b). The thickness and diameter of the irregular HTC particles on the surface increased with increasing concentration of the glucose solution. Furthermore, the distinct MHTCL was observed on the surface in the $10 \mathrm{~g} \mathrm{~L}^{-1}$ glucose solution; this glucose concentration is far below that in which classical HTC spheres are prepared..$^{38}$ For glucose concentrations above $15 \mathrm{~g} \mathrm{~L}^{-1}$, many micron scale irregular particles formed on the CFs. However, the thickness of the micron-scale particles on the CFs decreased for glucose solution concentrations over $40 \mathrm{~g} \mathrm{~L}^{-1}$. Most likely, in the high-concentration glucose solution, the classic hydrothermal carbonization process was the dominant process forming carbon spheres, which resulted in the decrease of the micron-scale particle thickness on the CF surface. The size of the micron scale irregular particles range from $50 \mathrm{~nm}$ to $2000 \mathrm{~nm}$. The number of the particles on the every $10 \mu \mathrm{m}$ long CF ranges from 1 to 50. The CF diameters did not clearly increase with increasing glucose concentration in the hydrothermal treatment. The thickness of the continuous part of the MHTCL was no more than $50 \mathrm{~nm}$, as judged by the fracture of the MHTCL, which is consistent with the thickness of HTC layers on $\mathrm{TiO}_{2} \cdot{ }^{39}$ Fracture of the MHCTLs was observed, as highlighted in Fig. 1(d-f) and (i-l). The fracture and rupture of the MHTCL led to the formation of unstable nanoparticles, which became the new nucleation centers during the HTC growth. It is difficult to detect the fracture and rupture of the MHTCL in the SEM images because the newly formed HTC covered the broken layers in the hydrothermal treatment. As observed in Fig. 1(i), the newly formed nanoparticles appeared on the bare part of the CF surface, which lost the MHTCL during the rupture. In most of the SEM images of the MHTCL, there were only irregular microparticles and a nanosized continuous HTC film or nano-sized discontinuous HTC particles on the CFs. Because of the stress of crosslinking, carbonization, and condensation in the superficial MHTCL and high elasticity modulus of the inner CFs, the fracture and rupture occurred endlessly during the growth of the MHTCL.

\subsection{Raman spectra}

Fig. 2 presents Raman spectra of the unsized CFs, MHTCLmodified CFs, and by-product hydrothermal carbon spheres (CSs) in the residues. The samples were characterized by two broad overlapping bands at approximately $1380 \mathrm{~cm}^{-1}$ (D-mode) and $1587 \mathrm{~cm}^{-1}$ (G-mode); the ratio of their intensities, $I(\mathrm{D}) / I(\mathrm{G})$, reveal the disorder of the carbon materials. However, in amorphous carbons, the development of a D peak indicates ordering, exactly the opposite from the case of graphite. ${ }^{40}$ There is nearly no D peak and a very small D peak in the spectra of CF4 and the by-product CSs, respectively, which indicates the high disorder of the carbon structure on the sample surfaces. The spectra of the heat-treated samples showed an obvious $\mathrm{D}$ peak because of the further aromatization during the heat treatment and increase of the ordering. ${ }^{41}$

The D and G bands of the MHTCL-modified CFs were similar to those of the by-product CSs and had the same peak positions as previously reported hydrothermal CSs; ${ }^{\mathbf{4 2 - 4 5}}$ the Raman spectra differed greatly from those of the CFs. It was verified that the surfaces of the hydrothermal treated CFs were completely covered by the MHTCL, a highly disordered amorphous carbon layer. 


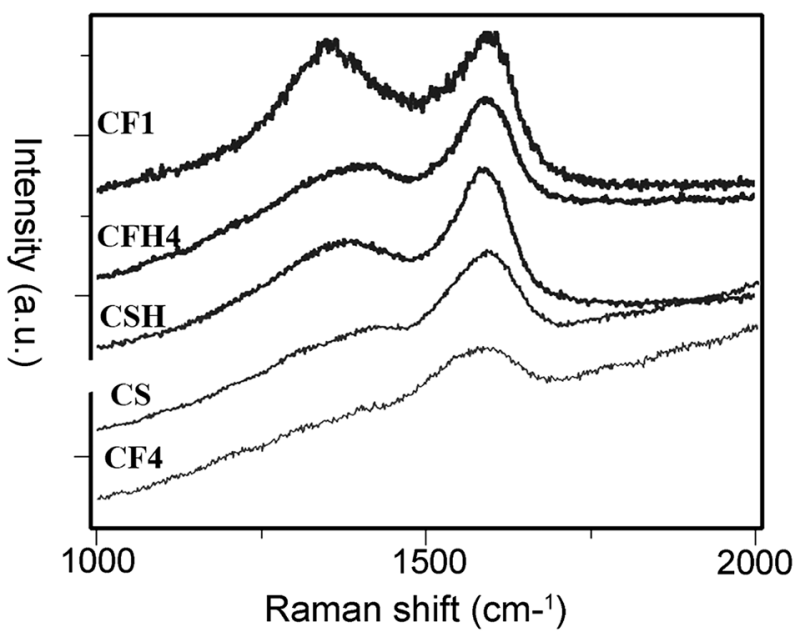

Fig. 2 Raman spectra of select samples described in Table 1.

\subsection{XPS analysis}

The unsized CFs and MHTCL-modified CFs were characterized by XPS. Consistent with previous reports, ${ }^{46,47}$ the $\mathrm{C} 1 \mathrm{~s}$ spectra peak of the MHTCL-modified CFs shifted to higher binding energy (BE) because of the increase of the sp3 carbon atoms in the MHTCL, in contrast with that of the unsized CFs (Fig. S5, $\mathrm{ESI} \dagger$ ). As observed in Fig. 3, the O/C atomic ratios of the CFs treated in solutions with different glucose concentrations were determined by XPS. The surface $\mathrm{O} / \mathrm{C}$ atomic ratio of the unsized CFs was 0.09 , and that of sample CF2 was 0.17 . The $\mathrm{O} / \mathrm{C}$ atomic ratios gradually increased with increasing glucose solution concentration used in the hydrothermal treatment. From these results, it can be inferred that the surface of the CFs was covered by MHTCL for the $2 \mathrm{~g} \mathrm{~L}^{-1}$ glucose solution hydrothermal treatment, which is consistent with the SEM images and Raman spectra.

The increase of the glucose concentration led to only a slight increase of the roughness of the MHTCL, as observed in Fig. 1. The $\mathrm{O} / \mathrm{C}$ ratios of the MHTCL surface did not change with the glucose concentration. ${ }^{\mathbf{4 8}}$ The increase of roughness led to an increase in the number of oxygen atoms on the top

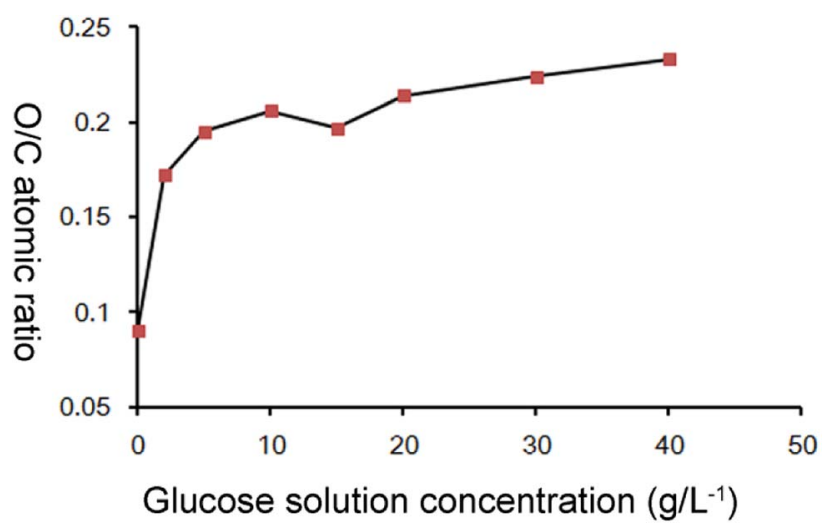

Fig. $3 \mathrm{O} / \mathrm{C}$ atomic ratios on CF surface vs. glucose concentration used in hydrothermal treatment.
Table 2 Carbon fiber surface energies and contact angles in different liquids $^{a}$

\begin{tabular}{|c|c|c|c|c|c|}
\hline \multirow[b]{2}{*}{ Samples } & \multicolumn{2}{|c|}{ Contact angle $\left(\theta^{\circ}\right)$} & \multicolumn{3}{|c|}{$\begin{array}{l}\text { OWRK surface } \\
\text { energy } \mathrm{mN} \mathrm{m}^{-1}\end{array}$} \\
\hline & $\begin{array}{l}\text { Deionized } \\
\text { water }\end{array}$ & Diiodomethane & $\gamma^{P}$ & $\gamma^{\mathrm{D}}$ & $\gamma^{\mathrm{T}}$ \\
\hline CF1 & $83.4(1.8)$ & $38.5(0.9)$ & 1.89 & 40.60 & 42.49 \\
\hline $\mathrm{CF} 4$ & $60.2(1.7)$ & $50.5(1.1)$ & 14.48 & 33.91 & 48.38 \\
\hline
\end{tabular}

surface of the samples, leading to a gradual increase of the $\mathrm{O} / \mathrm{C}$ atomic ratio determined by XPS which only detect the surficial atoms. The $\mathrm{O} / \mathrm{C}$ ratios of the $\mathrm{CF}$ surface are consistent with those of previously reported HTC spheres and oxidized CFs. ${ }^{42,48,49}$ The curve fit of the XPS spectra indicates that the oxygen atoms originate from $\mathrm{C}-\mathrm{O}$ groups and a small amount of $\mathrm{C}=\mathrm{O}$ groups (Fig. S4, ESI $\dagger$ ), which is in agreement with the wildly accepted furan-rich HTC carbon structure. ${ }^{50}$

\subsection{Surface energy of MHTCL-modified CFs}

The advancing contact angles (CAs) in the deionized water and diiodomethane and surface energies of the samples are summarized in the Table 2. As expected, the MHTCL-modified CFs exhibited decreased CAs in the liquids and increased total surface energies $\left(\gamma^{\mathrm{T}}\right)$ compared with those of the unsized CFs. The polar component $\left(\gamma^{\mathrm{P}}\right)$ of the MHTCL-modified CFs was 6 times larger than that of the unsized CFs as a result of the abundant functional groups of the MHTCL. The dispersive component $\left(\gamma^{\mathrm{D}}\right)$ greatly decreased after the hydrothermal treatment, possibly because the MHTCL increased the roughness and absorbed the air into the micro-nano structure during the wetting process of the CFs. The micro-nano structure may have differed from the classical superhydrophilic rough structure. ${ }^{51}$

The $\gamma^{\mathrm{P}}$ and $\gamma^{\mathrm{T}}$ values of the CFs clearly increased after hydrothermal treatment. Wetting of the fibers by the polymer is a prior condition of good fiber matrix adhesion; these functional groups $(\mathrm{C}-\mathrm{O} ; \mathrm{C}=\mathrm{O})$ may play an important role in fiber/ matrix adhesion by forming chemical bonding or hydrogen bonding between the fiber and matrix. ${ }^{15}$ Hydrogen bonding interactions are known to be important for fiber-matrix adhesion, and these interactions can be evaluated by investigating the $\gamma^{\mathrm{P}}$ of the surfaces. ${ }^{\mathbf{1 6 , 5 2}}$ Therefore, the distinct increase of $\gamma^{\mathrm{P}}$ and $\gamma^{\mathrm{T}}$ of the MHTCL-modified CFs may greatly improve the interaction of the CF and matrix.

Table 3 Surface area and composite evaluation of unsized CFs and MHTCL-modified CFs

\begin{tabular}{lll}
\hline Sample & $\begin{array}{l}\text { BET surface area } \\
\text { of the CFs } \mathrm{m}^{2} \mathrm{~g}^{-1}\end{array}$ & $\begin{array}{l}\text { Interlaminate shear strength } \\
\text { of the CF/PI composites MPa }\end{array}$ \\
\hline CF1 & 0.44 & 67.7 \\
CF4 & 1.03 & 92.5
\end{tabular}




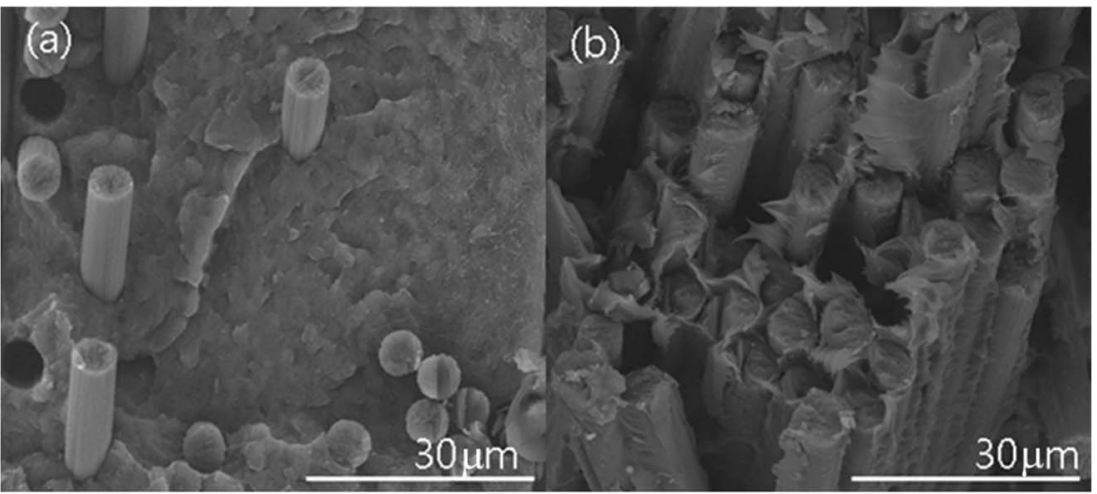

Fig. 4 SEM image of the CF/PEEK composite rupture face. Image (a) is the unsized CF (CF1) composite; image (b) is the MHTCL CF (CF4) composite.

\subsection{BET analysis of CFs and interfacial interaction evaluation of the their composites}

The CF's BET surface area clearly increased after MHTCL modification, as shown in Table 3. The distinct increase of the toughness, specific surface area, organic functional groups, and surface energy will greatly improve the interfacial interaction.
The interlaminate shear strength of the MHTCL CF/PI composite dramatically increased compared with that of the unsized CFs, as detected by short beam shear testing in accordance with ASTM D2344. The interfacial interaction was also improved in the CF/PEEK composite fabrication, as shown in Fig. 4 . The rupture face of MHTCL CF/PEEK composite is matrix

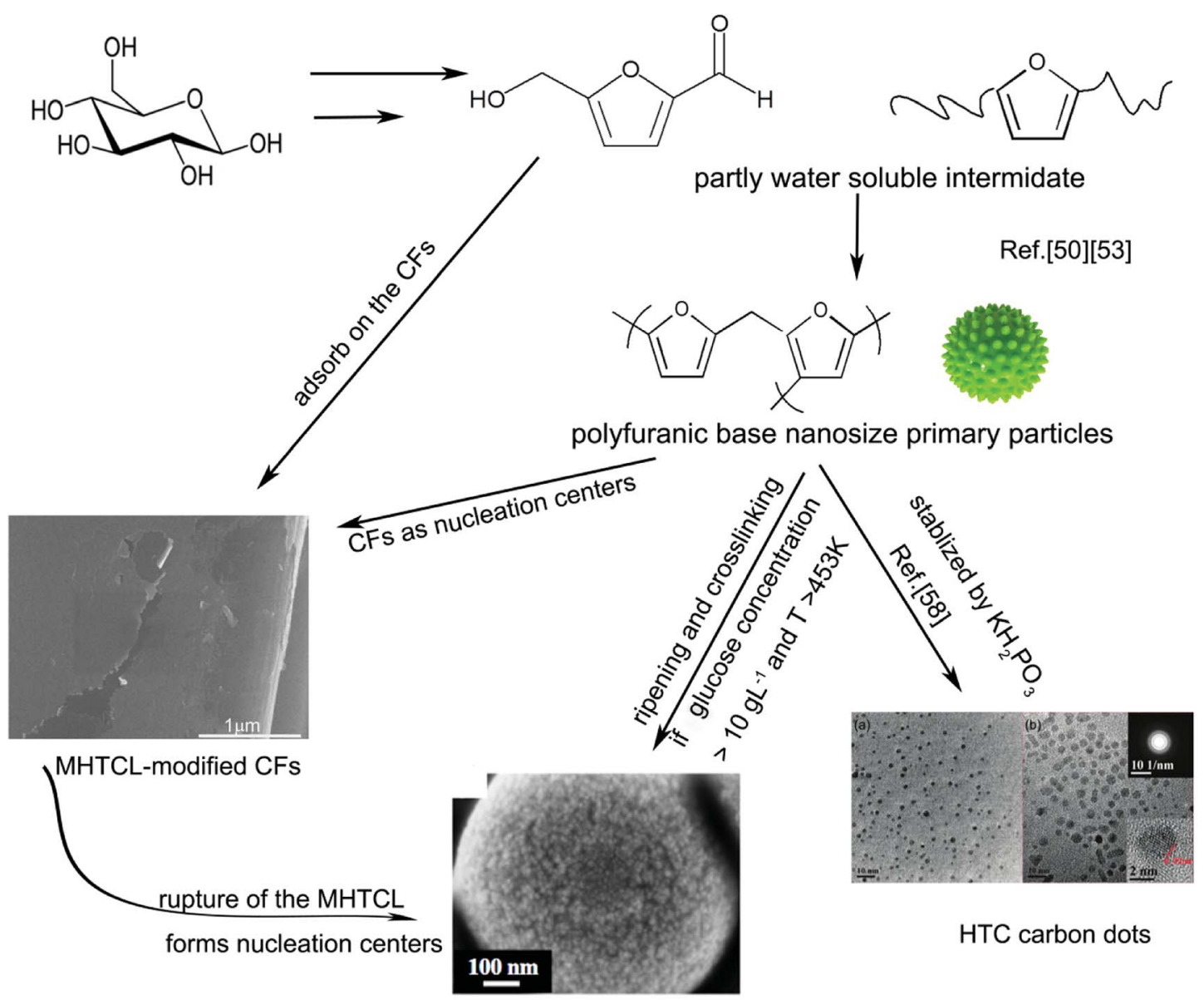

HTC sphere Ref. [53]

Fig. 5 Possible formation mechanism of MHTCL. The images of the HTC sphere and HTC carbon dots were reproduced with permission, ${ }^{53,58}$ Copyright Year 2012, Elsevier and Copyright Year 2011, Royal Society of Chemistry. 
rupture but that of unsized CF interface rupture, which means the MHTCL CF/PEEK composite has better interfacial interaction. ${ }^{11}$

\subsection{Possible formation mechanism of MHTCL on CFs}

The possible MHTCL formation mechanism is depicted in Fig. 5. The hydrothermal carbonization mechanism was illustrated by Sevilla, Titirici, and Xue et al. ${ }^{42,50,53}$ During hydrothermal treatment at $473 \mathrm{~K}$, the glucose transforms into a series of water-soluble substances (WSS) and partly watersoluble substances (PWSS), mainly furan derivatives, which undergo complex chemical reactions and form polyfuranic intermediates. ${ }^{29,42,50,54}$ TEM and SEM research on HTC spheres has shown that the nano-size spheres spread all over the surface of the HTC spheres, ${ }^{53,55}$ and it has been inferred that the nano-size primary polyfuranic particle is the intermediate. ${ }^{53}$ Considering that the nano-size primary polyfuranic particle is derived from WSS or PWSS in water solution, abundant hydrophilic groups must be reserved on the surface to maintain the low interfacial tension in the solution, similar to water-soluble Nano carbon dots prepared under the same experimental condition. However, in the hydrothermal reaction, the hydrophilicity of the groups is weakened because of the breakage of the hydrogen bonding between the oxygen in the groups and water at high temperature. ${ }^{56}$ Therefore, the plentiful hydrophilic groups cannot stabilize the primary particles well in the high-temperature hydrothermal solution above the critical concentration, and the ripening, aggregation, and crosslinking of the primary nanoparticles finally form the HTC spheres. As a result, the hydrothermal nanocarbon dots can be separated from the hydrothermal solutions with a low yield, as not all of the primary particles transform into microspheres. ${ }^{57}$ If the $\mathrm{KH}_{2} \mathrm{PO}_{3}$ is added to the glucose solution to stabilize the nanoparticles, the yield of the nano-carbon dots increases markedly. ${ }^{58}$

In this study, there was no precipitate or dispersion in the solutions for the glucose concentrations below $15 \mathrm{~g} \mathrm{~L}^{-1}$. The concentrations of the primary particles may have been below the critical concentration for precipitate growth in the clean glass tubes, which have a very low interface tension with the solution. With the addition of the CFs, the PWSS were absorbed on the CFs to decrease the interfacial tension of the CFs in the solution. In a similar manner, the CFs play the role of nucleation centers, and the unstable primary particles assemble on the CF surfaces. The intermediate substances are absorbed, assemble and carbonize on the CFs, form the MHTCL in a very low concentration glucose solution, in which the HTC cannot be prepared without CFs. The MHTCL thickness does not noticeably increase with increasing glucose solution concentration because of the fracture and rupture of the MHTCL, as previously discussed. The fractures of the MHTCL also produce nanoparticles as new nucleation centers on the CFs or in the glucose solution, which forms the particles on the CFs or the carbon spheres in the solution, respectively. The latter forms the cloudy dispersion liquid or sediments in the test tubes (Fig. S1b, ESI $\dagger$ ). The rupture of the MHTCL and the recovery of the HTC continue throughout the hydrothermal treatment, which leads to multiscale irregular particles on the MHTCL.

\section{Conclusions}

This study introduced hydrothermal carbonization as a novel carbon fiber surface modification method. The MHTCLs were synthesized on unsized CFs in glucose solution at a very low concentration. The MHTCL was verified to be a highly disordered amorphous carbon layer with abundant polar organic groups and multiscale roughness. The formation mechanism of the MHTCL was discussed. The CF plays the role of a nucleation center in the hydrothermal process, which leads to the formation of the MHTCL. The fracture and rupture of the MHTCL lead to multiscale roughness of the MHTCL. The nano-thickness continuous part and nanoparticles of the MHTCL provide evidence confirming that the widely accepted polyfuranic intermediate is a nano-size particle in the hydrothermal process. The intermediate may be a bridge between the HTC carbon dots and HTC carbon spheres in the formation mechanism. The distinct increase of the surface energy, specific surface area, toughness, and organic functional groups of the MHTCL-modified CFs improved the wetting ability of the CFs and noticeably increased the interfacial interaction of the $\mathrm{CF}$ and matrix in the $\mathrm{CF} /$ composite fabrication. The in situ MHTCL preparation on the CFs is a convenient method to improve the interfacial interaction of the CF composites.

\section{Conflicts of interest}

The authors have declared no conflicts of interest.

\section{Acknowledgements}

The authors gratefully acknowledge financial support received from the National Natural Science Foundation of China (Grant No. 91426304) and Strategic Priority Research Program of the Chinese Academy of Sciences (Grant No. XDA03010305).

\section{References}

1 M. Sharma, S. Gao, E. Mäder, H. Sharma, L. Y. Wei and J. Bijwe, Carbon fiber surfaces and composite interphases, Compos. Sci. Technol., 2014, 102, 35-50.

2 Z. Dai, F. Shi, B. Zhang, M. Li and Z. Zhang, Effect of sizing on carbon fiber surface properties and fibers/epoxy interfacial adhesion, Appl. Surf. Sci., 2011, 257(15), 69806985.

3 F. Gnädinger, P. Middendorf and B. Fox, Interfacial shear strength studies of experimental carbon fibres, novel thermosetting polyurethane and epoxy matrices and bespoke sizing agents, Compos. Sci. Technol., 2016, 133, 104-110.

4 M. A. Downey and L. T. Drzal, Toughening of carbon fiberreinforced epoxy polymer composites utilizing fiber surface treatment and sizing, Composites, Part A, 2016, 90, 687-698. 
5 C. Fang, J. Wang and T. Zhang, Interlaminar improvement of carbon fiber/epoxy composites via depositing mixture of carbon nanotubes and sizing agent, Appl. Surf. Sci., 2014, 321, 1-9.

6 K. M. Beggs, L. Servinis, T. R. Gengenbach, M. G. Huson, B. L. Fox, L. C. Henderson, et al., A systematic study of carbon fibre surface grafting via in situ diazonium generation for improved interfacial shear strength in epoxy matrix composites, Compos. Sci. Technol., 2015, 118, 31-38.

7 A. J. Vukov, D. G. Gray, Properties of Carbon Fiber Surfaces, Inverse Gas Chromatography chapter, vol. 13, 1989, pp. 168184.

8 Y. Liu, X. Zhang, C. Song, Y. Zhang, Y. Fang, B. Yang and $X$. Wang, An effective surface modification of carbon fiber for improving the interfacial adhesion of polypropylene composites, Mater. Des., 2015, 88, 810-819.

$9 \mathrm{H}$. He, K. Li and F. Gao, Improvement of the bonding between carbon fibers and an epoxy matrix using a simple sizing process with a novolac resin, Constr. Build. Mater., 2016, 116, 87-92.

10 R. L. Zhang, Y. D. Huang, D. Su, L. Liu and Y. R. Tang, Influence of sizing molecular weight on the properties of carbon fibers and its composites, Mater. Des., 2012, 34, 649-654.

11 I. Giraud, S. Franceschi, E. Perez, C. Lacabanne and E. Dantras, Influence of new thermoplastic sizing agents on the mechanical behavior of poly(ether ketone ketone)/ carbon fiber composites, J. Appl. Polym. Sci., 2015, 132(38).

12 J. S. Kim and D. H. Kim, Compatibilizing effects of maleic anhydride-grafted-polypropylene (PP)on long carbon fiberreinforced PP composites, J. Thermoplast. Compos. Mater., 2014, 28(11), 1599-1611.

13 L. A. Savas, U. Tayfun and M. Dogan, The use of polyethylene copolymers as compatibilizers in carbon fiber reinforced high density polyethylene composites, Composites, Part B, 2016, 99, 188-195.

$14 \mathrm{H}$. Yuan, S. Zhang and C. Lu, Surface modification of carbon fibers by a polyether sulfone emulsion sizing for increased interfacial adhesion with polyether sulfone, Appl. Surf. Sci., 2014, 317, 737-744.

15 N. Dilsiz and J. P. Wightman, Surface analysis of unsized and sized carbon fibers, Carbon, 1999, 37, 1105-1114.

16 Y. Luo, Y. Zhao, Y. Duan and S. Du, Surface and wettability property analysis of CCF300 carbon fibers with different sizing or without sizing, Mater. Des., 2011, 32(2), 941-946.

17 R. Seemann, S. Herminghaus and K. Jacobs, Dewetting patterns and molecular forces: a reconciliation, Phys. Rev. Lett., 2001, 86(24), 5534-5537.

18 B. H. Kim, D. H. Lee, K. S. Yang, B. C. Lee, Y. A. Kim and M. Endo, Electron beam irradiation-enhanced wettability of carbon fibers, ACS Appl. Mater. Interfaces, 2011, 3, 119123.

19 F. Vautard, J. Dentzer, M. Nardin, J. Schultz and B. Defoort, Influence of surface defects on the tensile strength of carbon fibers, Appl. Surf. Sci., 2014, 322, 185-193.
20 S. He, C. Lu and S. Zhang, Facile and efficient route to polyimide- $\mathrm{TiO}_{2}$ nanocomposite coating onto carbon fiber, ACS Appl. Mater. Interfaces, 2011, 3(12), 4744-4750.

21 M. Sharma, J. Bijwe and P. Mitschang, Wear performance of PEEK-carbon fabric composites with strengthened fibermatrix interface, Wear, 2011, 271(9-10), 2261-2268.

22 D. I. Chukov, A. A. Stepashkin, A. V. Maksimkin, V. V. Tcherdyntsev, S. D. Kaloshkin, K. V. Kuskov and V. I. Bugakov, Investigation of structure, mechanical and tribological properties of short carbon fiber reinforced UHMWPE-matrix composites, Composites, Part B, 2015, 76, 79-88.

23 B. Gao, R. Zhang, M. He, L. Sun, C. Wang, L. Liu, L. Zhao, H. Cui and A. Cao, Effect of a multiscale reinforcement by carbon fiber surface treatment with graphene oxide/carbon nanotubes on the mechanical properties of reinforced carbon/carbon composites, Composites, Part A, 2016, 90, 433-440.

24 F. Cuiqin, W. Jinxian, W. Julin and Z. Tao, Modification of carbon fiber surfaces via grafting with Meldrum's acid, Appl. Surf. Sci., 2015, 356, 9-17.

25 X. Zhang, X. Fan, C. Yan, H. Li, Y. Zhu, X. Li, et al., Interfacial microstructure and properties of carbon fiber composites modified with graphene oxide, ACS Appl. Mater. Interfaces, 2012, 4(3), 1543-1552.

26 Q. Zhang, J. Wu, L. Gao, T. Liu, W. Zhong, G. Sui and X. Yang, Influence of a liquid-like MWCNT reinforcement on interfacial and mechanical properties of carbon fiber filament winding composites, Polymer, 2016, 90, 193-203.

27 J. Sun, H. Li, L. Feng, Y. Jia, Q. Song and K. Li, A novel treatment of carbon fibers with improving tensile strength to synthesize evenly distributed carbon nanotubes on their surface, Appl. Surf. Sci., 2017, 403, 95-102.

28 L. Feng, K.-Z. Li, J.-H. Lu and L.-H. Qi, Effect of Growth Temperature on Carbon Nanotube Grafting Morphology and Mechanical Behavior of Carbon Fibers and Carbon/ Carbon Composites, J. Mater. Sci. Technol., 2017, 33(1), 6570 .

29 M. Sevilla and A. B. Fuertes, The production of carbon materials by hydrothermal carbonization of cellulose, Carbon, 2009, 47(9), 2281-2289.

30 H. Cai, X. Lin, Y. Qin and X. Luo, Hydrothermal synthesis of carbon microsphere from glucose at low temperature and its adsorption property of uranium(vi), J. Radioanal. Nucl. Chem., 2016, 311(1), 695-706.

31 R. Yang, X. Qiu, H. Zhang, J. Li, W. Zhu, Z. Wang, X. Huang and L. Chen, Monodispersed hard carbon spherules as a catalyst support for the electrooxidation of methanol, Carbon, 2005, 43(1), 11-16.

32 H. Ma, J. Li, W. Liu, B. Cheng, X. Cao, J. Mao and S. Zhu, Hydrothermal preparation and characterization of novel corncob-derived solid acid catalysts, J. Agric. Food Chem., 2014, 62(23), 5345-5353.

33 G. Wen, B. Wang, C. Wang, J. Wang, Z. Tian, R. Schlogl and D. S. Su, Hydrothermal Carbon Enriched with Oxygenated Groups from Biomass Glucose as an Efficient Carbocatalyst, Angew. Chem., 2017, 56(2), 600-604. 
34 V. G. Pol, E. Lee, D. Zhou, F. Dogan, J. M. Calderon-Moreno and C. S. Johnson, Spherical Carbon as a New High-Rate Anode for Sodium-ion Batteries, Electrochim. Acta, 2014, 127, 61-67.

35 Y. Sha, L. Li, S. Wei and Z. Shao, Appraisal of carbon-coated $\mathrm{Li}_{4} \mathrm{Ti}_{5} \mathrm{O}_{12}$ acanthospheres from optimized two-step hydrothermal synthesis as a superior anode for sodium-ion batteries, J. Alloys Compd., 2017, 705, 164-175.

$36 \mathrm{~J} . \mathrm{Hu}, \mathrm{H}$. Li and X. Huang, Influence of micropore structure on Li-storage capacity in hard carbon spherules, Solid State Ionics, 2005, 176(11-12), 1151-1159.

37 R. G. Mendes, A. Bachmatiuk, B. Büchner, G. Cuniberti and M. H. Rümmeli, Carbon nanostructures as multi-functional drug delivery platforms, J. Mater. Chem. B, 2013, 1(4), 401428.

38 M. M. Titirici, M. Antonietti and N. Baccile, Hydrothermal carbon from biomass: a comparison of the local structure from poly- to monosaccharides and pentoses/hexoses, Green Chem., 2008, 10(11), 1204.

39 Y. Sha, L. Li, S. Wei and Z. Shao, Appraisal of carbon-coated $\mathrm{Li}_{4} \mathrm{Ti}_{5} \mathrm{O}_{12}$ acanthospheres from optimized two-step hydrothermal synthesis as a superior anode for sodium-ion batteries, J. Alloys Compd., 2017, 705, 164-175.

$40 \mathrm{~J}$. R. A. C. Ferrari, Interpretation of Raman spectra of disordered and amorphous carbon, Phys. Rev. B: Condens. Matter Mater. Phys., 2000, 61(20), 14095-14107.

41 A. B. Brown, B. J. McKeogh, G. A. Tompsett, R. Lewis, N. A. Deskins and M. T. Timko, Structural analysis of hydrothermal char and its models by density functional theory simulation of vibrational spectroscopy, Carbon, 2017, 125, 614-629.

42 M. Sevilla and A. B. Fuertes, Chemical and structural properties of carbonaceous products obtained by hydrothermal carbonization of saccharides, Chem.-Eur. J., 2009, 15, 4195-4203.

43 M. Inada, N. Enomoto, J. Hojo and K. Hayashi, Structural analysis and capacitive properties of carbon spheres prepared by hydrothermal carbonization, Adv. Powder Technol., 2017, 28(3), 884-889.

44 O. Haibo, L. Cuiyan, H. JianFeng and F. Jie, Synthesis of carbon/carbon composites by hydrothermal carbonization using starch as carbon source, RSC Adv., 2014, 4(24), 12586-12589.

45 X. Sun and Y. Li, Colloidal carbon spheres and their core/ shell structures with noble-metal nanoparticles, Angew. Chem., 2004, 43(5), 597-601.

46 P. Mérel, M. Tabbal, M. Chaker, S. Moisa and J. Margot, Direct evaluation of the sp3 content in diamond-likecarbon films by XPS., Appl. Surf. Sci., 1998, 136, 105-110.
47 G. P. Javier Díaz, S. Ferrer and F. Comin, Separation of the $\operatorname{sp}(3)$ and $\operatorname{sp}(2)$ components in the $\mathrm{C} 1 \mathrm{~s}$ photoemission spectra of amorphous carbon films pdf, Phys. Rev. B, 1996, 54, 8064.

48 J. Ryu, Y.-W. Suh, D. J. Suh and D. J. Ahn, Hydrothermal preparation of carbon microspheres from monosaccharides and phenolic compounds, Carbon, 2010, 48(7), 1990-1998.

49 Z. R. Yue, W. Jiang, L. Wang, S. D. Gardner and C. U. Pittman, Surface characterization of electrochemically oxidized carbon fibers, Carbon, 1999, 37(11), 1785-1796.

50 C. Falco, N. Baccile and M.-M. Titirici, Morphological and structural differences between glucose, cellulose and lignocellulosic biomass derived hydrothermal carbons, Green Chem., 2011, 13(11), 3273.

51 Y. Tian, B. Su and L. Jiang, Interfacial material system exhibiting superwettability, Adv. Mater., 2014, 26(40), 68726897.

52 N. Gamze Karsli, C. Ozkan, A. Aytac and V. Deniz, Characterization of poly(butylene terephthalate) composites prepared by using various types of sized carbon fibers, Mater. Des., 2015, 87, 318-323.

53 M. Zhang, H. Yang, Y. Liu, X. Sun, D. Zhang and D. Xue, Hydrophobic precipitation of carbonaceous spheres from fructose by a hydrothermal process, Carbon, 2012, 50(6), 2155-2161.

54 K. G. Latham, A. Rawal, J. M. Hook, et al., Molecular Structures Driving Pseudo-Capacitance in Hydrothermal nanostructured carbons, RSC Adv., 2016, 6(16), 1296412976.

55 R. Demir-Cakan, N. Baccile, M. Antonietti and M.-M. Titirici, Carboxylate-Rich Carbonaceous Materials via One-Step Hydrothermal Carbonization of Glucose in the Presence of Acrylic Acid, Chem. Mater., 2009, 21, 484-490.

56 A. Rastogi, A. K. Ghosh and S. J. Suresh, Hydrogen bond interactions between water molecules in bulk liquid, near electrode surfaces and around ions, in Thermodynamics Physical Chemistry of Aqueous Systems, ed. J. C. MorenoPiraján, InTech, 2011, pp. 351-364.

57 Z. Gao, X. Wang, J. Chang, D. Wu, L. Wang, X. Liu, F. Xu, Y. Guo and K. Jiang, Fluorescent carbon quantum dots, capacitance and catalysis active porous carbon microspheres from beer, RSC Adv., 2015, 5(60), 48665-48674. 58 Z.-C. Yang, A. Marie Yong, S. Yee Wong, X.-H. Zhang, A. Y. C. Happy Tan, X. Li and J. Wang, Intrinsically fluorescent carbon dots with tunable emission derived from hydrothermal treatment of glucose in the presence of monopotassium phosphate, Chem. Commun., 2011, 47, 11615. 